\title{
Chemical Profiling and Constituent Diversity in Nutmeg Genotypes (Myristica fragrans Houtt.)
}

\author{
H.C. Vikram, N. Mini Raj, Deepu Mathew, S.C. Priyanka, V.S. Sujatha
}

10.18805/IJARe.A-5848

\begin{abstract}
Background: Nutmeg is a perennial tree spices which is yielding twin spices; present days research thrust is to identify high yielding mother trees. But yield and quality both are equally important due to its wide spread medicinal as well as industrial usage.

Methods: The core collection of nutmeg genotypes form different locations of Kerala evaluated for biochemical composition. Seventeen morphologically distinct types of nutmeg were analysed through GC/MS method. The change in volatiles after storage (at $\left.4^{\circ} \mathrm{C}\right)$ was also assessed after one year.

Result: The range of variation was observed for kernel oil, mace oil, kernel oleoresin, mace oleoresin and fixed oil of kernel. Myristicin, elemecin and sabinene were principal volatile compounds. The identification of distinct nutmeg chemotypes for specific volatile compounds which could be used in commercial cultivation/pharmaceutical application/industrial use. Present study highlights the high and low hallucinogen (myristicine, elemicine and safrole) genotypes along with high sabinene types.
\end{abstract}

Key words: Chemoprofiling, Fixed oil, Myristica fragrans, Oleoresin, Volatile oil.

\section{INTRODUCTION}

Myristica fragrans Houtt. is the only cultivated species of nutmeg which yields twin spices; nutmeg and mace, both having tremendous potential in the spice industry. It is used for food, flavouring and as ingredient in many of the value added products due to the presence of a unique spectrum of flavour compounds. Indonesia is the world leader in production and export of nutmeg and mace, followed by Graneda. As of now, the nutmeg is mainly cultivated in Southern India particularly in all the districts of Kerala and certain parts of Tamil Nadu and Karnataka. The present area under this crop in India is 24252 ha with an annual production of 15688 tonnes (DASD, 2021).

The volatile oil from this plant is extensively used in the pharmaceutical industry. The volatile oil is used externally for treating rheumatism and internally as a carminative. It is also used in soaps and in aroma therapy as postpartum medication (Warsito, 2021). The hepatoprotective property of the essential oil is attributed to the presence of lignans, phenols and the phenyl-propanoids commonly found in Myristicaceae (Sharma et al., 2000). The anti-inflammatory and antipyretic activities of the nutmeg have been scientifically proven (Kapoor et al., 2013). Unlike other crops, where thrust is given on yield maximization of nutmeg, apart from yield, quality is equally important because of its wide spread medicinal as well as industrial usage. Comprehensive characterization of nutmeg for the contents of volatile oil, oleoresin and fixed oil and for constituents of volatile oil is very much limited. In this study, we have evaluated a core collection of nutmeg having genotypes form different locations of Kerala, India for biochemical composition and further the volatile oils of morphologically distinct types were subjected to GC/MS analysis. The
Centre for Plant Biotechnology and Molecular Biology, College of Agriculture, Kerala Agricultural University,Thrissur-680 656, Kerala, India.

Corresponding Author: H.C. Vikram, College of Agriculture, Kerala Agricultural University, Thrissur-680 656, Kerala, India. Email: vikram.hc@kau.in

How to cite this article: Vikram, H.C., Raj, N.M., Mathew, D., Priyanka, S.C. and Sujatha, V.S. (2022). Chemical Profiling and Constituent Diversity in Nutmeg Genotypes (Myristica fragrans Houtt.). Indian Journal of Agricultural Research. DOI: 10.18805/ IJARe.A-5848.

Submitted: 11-06-2021 Accepted: 11-12-2021 Online: 07-01-2022

change in volatiles after storage was also assessed after one year.

\section{MATERIALS AND METHODS}

Nutmeg accessions selected from a core collection which are being maintained in the farmers plantations from Chalakudy river basin in the state of Kerala, India $\left(10^{\circ} 18^{\prime} \mathrm{N}\right.$ and $\left.76^{\circ} 20^{\prime} \mathrm{E}\right)$ formed the material for the study. The accessions were of same age group above 15 years and accessions represented all major nutmeg growing regions of Kerala state. After the evaluation of 46 accessions, 17 distinct accessions were selected based on $D^{2}$ analysis. These accessions were used for further chemoprofiling of volatile oil through GC/MS. The dried pulverised samples of kernel and mace were used for isolation of volatile oil (Clevenger, 1982), oleoresin (ASTA, 1968) and fixed oil (AOAC, 1975). GC/MS analysis of volatile oil was performed using Shimadzu GC/MS with standard operating procedures. Individual components were identified by comparing mass 
fragment pattern with the standard spectra of data base. The nutmeg accessions which yielded higher quantities of principal constituents were again subjected to GC/MS analysis after one year storage under refrigerator (at $4^{\circ} \mathrm{C}$ ) condition. The contents of volatile oil, oleoresin and fixed oil from the kernel and mace was calculated and expressed in percentage. The replicated data was subjected to analysis of variance using SPSS v.16 (SPSS, 2007).

\section{RESULTS AND DISCUSSION}

Volatile oil content in kernel ranged from 1.57 to $7.67 \mathrm{per}$ cent. Similarly, mace oil content ranged between 2.05 and 9.33 per cent. Genotype, Acc.22 (9.33\%) recorded highest mace volatile content. Genotypes, Acc.5, Acc.6, Acc.8, Acc.22 and Acc.34 registered high amounts of both kernel and mace volatile oils (Table 1). Oleoresin content in kernel varied from 18.59 to 36.20 per cent. Significantly the highest recovery of kernel oleoresin was recorded in Acc.40. In mace, oleoresin content varied from 11.38 to 31.66 per cent. Highest recovery of mace oleoresin was recorded in Acc.4. In all the genotypes, content of oleoresin was high in kernel compared to mace. In Acc.4, both the kernel and mace oleoresin contents were high. Fixed oil content in the kernel of various genotypes varied from 17.79 to 44.80 per cent. Significantly very high recovery of fixed oil was recorded in Acc.22. Abdurrasheed and Janardanan (2009) have recorded the fixed oil content of 33.80 per cent in nutmeg collected from northern districts of Kerala. Interestingly, genotypes, Acc.8, Acc.22 and Acc.38 were both high yielding as well as of high quality. These three genotypes could very well be categorised as high performing types which could be utilised for commercial cultivation, pharmaceutical applications and industrial utilisation.

Total volatile oil constituents of the genotypes ranged from 68.96 to 90.49 per cent in kernel and 83.96 to 93.89 per cent in mace (Tables 2 and 3). GC/MS analysis showed the presence of 20 and 24 constituents in kernel and mace oils, respectively. This variation in per cent composition of constituents may be due to genetic makeup of the accessions.

The prime compounds in the oil were myristicin, elemecin, sabinene and safrole. Apart from these, accessions also recorded higher percentages of alphapinene, beta-pinene and L-4-terpineol in kernel and mace oils. Chirathaworn et al. (2007) identified myristicin, eugenol, isoeugenol and elemecin as the major bioactive compounds in nutmeg oil. Myristicin content ranged from 2.98 to 12.84 per cent in kernel oil and 1.57 to 18.87 per cent in mace oil. Elemecin content was to the tune of 4.31 to 22.48 per cent in kernel oil and 1.39 to 27.86 per cent in mace oil. It was interesting to observe that, monoecious genotype, Acc. $(\mathrm{H})$ 1 had significantly higher myristicin and elemecin in both kernel as well as mace oils. Safrole content varied from 2.44 to 4.64 per cent in kernel oil and 2.96 to 4.89 per cent in mace oil. Sabinene content ranged from 1.06 to 11.75 per cent in kernel oil and 4.89 to 16.20 per cent in mace oil. Acc. 8 recorded significantly the highest sabinene in both kernel and mace oils. The notable difference between the kernel oil and mace oil was that, kernel oils contained higher level of L-4-terpineol, whereas it was low to medium in mace oils.

Genotypes, Acc.5 and Acc.(H) 1 were high myristicin as well as high elemecin containing chemotypes. Genotypes, Acc. 9 and Acc.36 were in the low myristicin group. Acc.9 was also low in elemecin along with Acc.35. High sabinene combined with low myristicin was the intrinsic quality attribute of Acc.9. Myristicin, elemecin and safrole are the hallucinogenic compounds in nutmeg oil, whereas sabinene imparts sweetness to the products. The present study has brought out high as also low hallucinogen containing genotypes along with high sabinene containing types. Higher content of myristicin, elemecin and safrole is preferred by the pharmaceutical sector, while sweet nutmegs with high sabinene content are preferred in the food sector. Lawrence (2000) also indicated about the variability in the constituents of kernel and mace oil.

Total number of compounds increased from 20 to 27 in kernel oil after one year of storage (Table 4). Among the samples, one sample (Acc.5) recorded overall per cent increase in constituents $(5.10 \%)$ whereas the other two samples (Acc.38 and Acc.(H) 1) showed losses of constituents on storage. Among the seven major constituents, only myristicin and elemecin contents increased substantially on storage in all the three samples. Both these compounds have extensive applications in the ayurveda and pharmaceutical sectors. Alpha-pinene, sabinene and beta-pinene contents decreased in all the three samples upon storage. Percentage of L-4-terpineol increased in Acc. 5 and Acc. $(\mathrm{H}) 1$ where as content of safrole increased in Acc.(H) 1. On storage of kernel volatile oils, nine additional compounds were detected.

One year storage period in four samples of mace volatile oil detected the presence of 30 compounds as against (Table 5) 24 compounds in fresh mace oil. Maximum percentage of change was recorded in Acc.21 (14.63\%) and minimum in Acc.11 (1.92\%). The content of elemecin increased in all the four samples of mace oil whereas myristicin level increased in three samples except Acc.21. Alpha-pinene, sabinene and bete-pinene contents decreased in all the four stored samples. On storage of mace oils, 13 additional compounds were detected. The increase or decrease in the relative concentration of volatile constituents may be due to the chemical transformations that occur during storage. Hafiz et al. (2019) studied the post storage changes of volatile compounds in air and sun dried raisins and opined that aroma profile increased after storage for 12 months. 
Chemical Profiling and Constituent Diversity in Nutmeg Genotypes (Myristica fragrans Houtt.)

Table 1: Volatile oil, oleoresin and fixed oil content in kernel and mace of nutmeg accessions.

\begin{tabular}{|c|c|c|c|c|c|}
\hline \multirow{2}{*}{ Accessions } & \multicolumn{2}{|c|}{ Volatile oil (\%) } & \multicolumn{2}{|c|}{ Oleoresin (\%) } & \multirow{2}{*}{$\begin{array}{l}\text { Fixed oil in } \\
\text { kernel }(\%)\end{array}$} \\
\hline & Kernel & Mace & Kernel & Mace & \\
\hline Acc. 1 & $4.32(2.30)$ & $6.33(2.70)$ & $32.20(5.76)$ & $26.33(5.22)$ & $28.52(5.43)$ \\
\hline Acc. 2 & $3.99(2.23)$ & $8.33(3.05)$ & $32.01(5.74)$ & $29.66(5.53)$ & $35.39(6.03)$ \\
\hline Acc. 3 & $4.24(2.28)$ & $6.67(2.76)$ & $29.40(5.51)$ & $21.99(4.79)$ & $32.80(5.81)$ \\
\hline Acc. 4 & $3.33(2.08)$ & $6.67(2.76)$ & $30.00(5.56)$ & $31.66(5.71)$ & $29.49(5.52)$ \\
\hline Acc. 5 & $6.99(2.82)$ & $6.33(2.70)$ & $27.39(5.32)$ & $17.67(4.32)$ & $26.70(5.26)$ \\
\hline Acc. 6 & $5.00(2.44)$ & $8.66(3.10)$ & $26.01(5.19)$ & $22.20(4.81)$ & $40.69(6.45)$ \\
\hline Acc. 7 & $6.67(2.76)$ & $4.65(2.37)$ & $26.00(5.19)$ & $26.32(5.22)$ & $40.50(6.44)$ \\
\hline Acc. 8 & $7.32(2.88)$ & $6.33(2.70)$ & $31.60(5.71)$ & $23.01(4.89)$ & $35.89(6.07)$ \\
\hline Acc. 9 & $6.00(2.64)$ & $5.67(2.58)$ & $35.20(6.01)$ & $17.33(4.28)$ & $23.67(4.96)$ \\
\hline Acc. 10 & $4.33(2.30)$ & $8.99(3.16)$ & $31.59(5.70)$ & $28.67(5.44)$ & $33.40(5.86)$ \\
\hline Acc. 11 & $5.67(2.58)$ & $6.34(2.71)$ & $24.16(5.01)$ & $24.17(5.01)$ & $28.40(5.42)$ \\
\hline Acc. 12 & $3.26(2.06)$ & $5.40(2.53)$ & $19.60(4.53)$ & $23.60(4.96)$ & $34.60(5.96)$ \\
\hline Acc. 13 & $3.67(2.16)$ & $7.33(2.88)$ & $26.21(5.21)$ & $15.32(4.04)$ & $26.50(5.24)$ \\
\hline Acc. 14 & $3.32(2.08)$ & $7.00(2.82)$ & $22.79(4.87)$ & $20.01(4.58)$ & $32.10(5.75)$ \\
\hline Acc. 15 & $4.67(2.38)$ & $6.67(2.76)$ & $33.40(5.86)$ & $15.99(4.12)$ & $36.99(6.16)$ \\
\hline Acc. 16 & $2.74(1.93)$ & $2.80(1.94)$ & $22.21(4.81)$ & $12.40(3.65)$ & $26.94(5.28)$ \\
\hline Acc. 17 & $5.99(2.64)$ & $6.33(2.70)$ & $26.66(5.25)$ & $22.20(4.81)$ & $37.10(6.17)$ \\
\hline Acc. 18 & $3.33(2.08)$ & $6.33(2.70)$ & $26.60(5.25)$ & $20.32(4.61)$ & $34.50(5.95)$ \\
\hline Acc. 19 & $3.33(2.08)$ & $3.74(2.17)$ & $29.59(2.53)$ & $23.00(4.89)$ & $24.40(5.04)$ \\
\hline Acc. 20 & $1.67(1.63)$ & $2.05(1.74)$ & $19.72(4.55)$ & $11.38(3.51)$ & $19.48(4.25)$ \\
\hline Acc. 21 & $5.67(2.58)$ & $6.25(2.69)$ & $32.80(5.81)$ & $19.33(4.50)$ & $28.89(5.46)$ \\
\hline Acc. 22 & $4.66(2.38)$ & $9.33(3.21)$ & $31.20(5.67)$ & $23.01(4.89$ & $44.80(6.76)$ \\
\hline Acc. 23 & 2.99 (1.99) & $7.37(2.89)$ & $23.80(4.98)$ & $16.67(4.20)$ & $35.59(6.04)$ \\
\hline Acc. 24 & $2.99(1.99)$ & $6.01(2.64)$ & $23.60(4.96)$ & $20.32(4.61)$ & $23.60(4.96)$ \\
\hline Acc. 25 & $4.99(2.44)$ & $6.33(2.70)$ & $31.2(5.67)$ & $23.01(4.89)$ & $26.59(5.25)$ \\
\hline Acc. 26 & $4.99(2.44)$ & $6.64(2.76$ & $22.40(4.83)$ & $29.33(5.50)$ & $25.00(5.09)$ \\
\hline Acc. 27 & $4.33(2.30)$ & $3.00(2.00)$ & $30.01(5.56)$ & $14.33(3.91)$ & $25.60(5.15)$ \\
\hline Acc. 28 & $1.57(1.60)$ & $2.41(1.84)$ & $20.23(4.60)$ & $12.27(3.64)$ & $17.79(4.33)$ \\
\hline Acc. 29 & $2.66(1.91)$ & $6.35(2.71)$ & $19.80(4.56)$ & $22.50(4.84)$ & $38.90(6.31)$ \\
\hline Acc. 30 & $4.33(2.30)$ & $7.19(2.86)$ & $18.59(4.42)$ & $17.60(4.31)$ & $29.99(5.56)$ \\
\hline Acc. 31 & $2.29(1.81)$ & $3.03(2.00)$ & $23.26(4.92)$ & $17.75(4.33)$ & $20.65(4.65)$ \\
\hline Acc. 32 & $1.67(1.63)$ & $4.56(2.35)$ & $28.60(5.44)$ & $19.20(4.49)$ & $25.69(5.16)$ \\
\hline Acc. 33 & $2.50(1.87)$ & $6.93(2.81)$ & $24.01(5.00)$ & $19.60(4.53)$ & $39.99(6.40)$ \\
\hline Acc. 34 & $7.67(2.94)$ & $8.01(3.00)$ & $25.33(5.13)$ & $24.80(5.07)$ & $29.49(5.52)$ \\
\hline Acc. 35 & $3.67(2.16)$ & $6.01(2.64)$ & $28.80(5.45)$ & 14.00 & $37.10(6.17)$ \\
\hline Acc. 36 & $2.33(1.82)$ & $7.33(2.88)$ & $30.33(5.59)$ & $23.20(4.91)$ & $34.19(5.93)$ \\
\hline Acc. 37 & $3.33(2.08)$ & $8.01(3.00)$ & $34.80(5.98)$ & $26.33(5.22)$ & $40.69(6.45)$ \\
\hline Acc. 38 & $1.92(1.70)$ & $8.33(3.05)$ & $26.20(5.21)$ & $17.33(4.28)$ & $41.73(6.53)$ \\
\hline Acc. 39 & $3.67(2.16)$ & $3.33(2.08)$ & $25.79(5.17)$ & $17.67(4.32)$ & $34.30(5.94)$ \\
\hline Acc. 40 & $3.00(2.00)$ & $6.66(2.76)$ & $36.20(6.09)$ & $19.00(4.47)$ & $27.90(5.37)$ \\
\hline Acc. 41 & $4.33(2.30)$ & $6.33(2.70)$ & $23.79(4.97)$ & $16.67(4.20)$ & $24.13(5.01)$ \\
\hline Acc. 42 & $3.67(2.16)$ & $6.33(2.70)$ & $26.40(5.23)$ & $16.33(4.16)$ & $28.41(5.42)$ \\
\hline Acc. $(\mathrm{H}) 1$ & $6.33(2.70)$ & $4.46(2.33)$ & $26.41(5.23)$ & $17.33(4.28)$ & $35.39(6.03)$ \\
\hline Acc. $(\mathrm{H}) 2$ & 2.97 (1.99) & $2.39(1.84)$ & $21.65(4.75)$ & $14.90(3.98)$ & $24.05(5.00)$ \\
\hline Acc. $(\mathrm{H}) 3$ & $4.00(2.23)$ & $8.14(3.02)$ & $24.33(5.03)$ & $21.40(4.73)$ & $35.70(6.05)$ \\
\hline Acc. $(\mathrm{H}) 4$ & $5.33(2.51)$ & $6.90(2.81)$ & $27.39(5.32)$ & $22.67(4.86)$ & $39.00(6.32)$ \\
\hline C.D (0.05) & $0.15(0.04)$ & $0.16(0.03)$ & $0.92(0.09)$ & $0.75(0.09)$ & $0.92(0.09)$ \\
\hline C.V (\%) & $1.81(0.88)$ & $1.34(0.62)$ & $1.69(0.90)$ & $1.81(1.06)$ & $1.45(0.78)$ \\
\hline
\end{tabular}

${ }^{*}$ Figures in parenthesis are square root transformed values. 


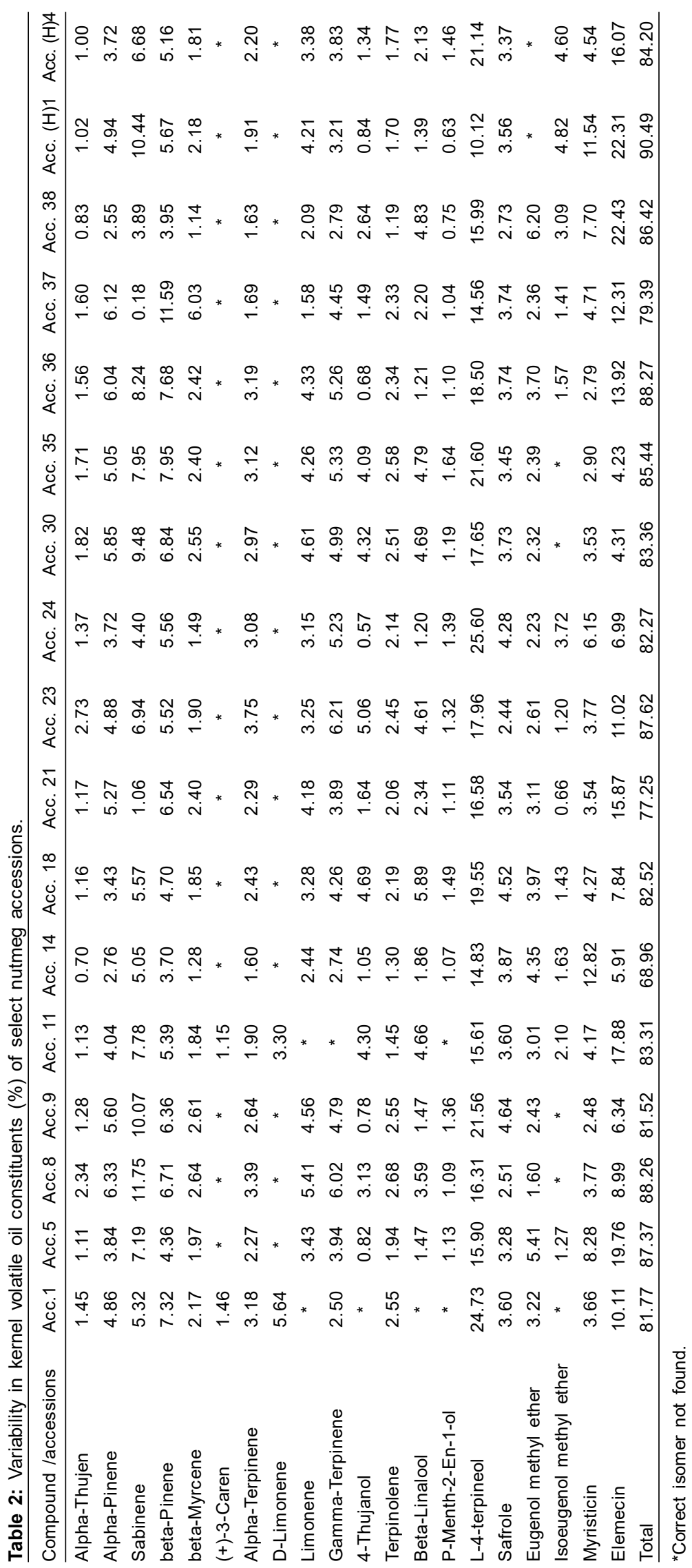




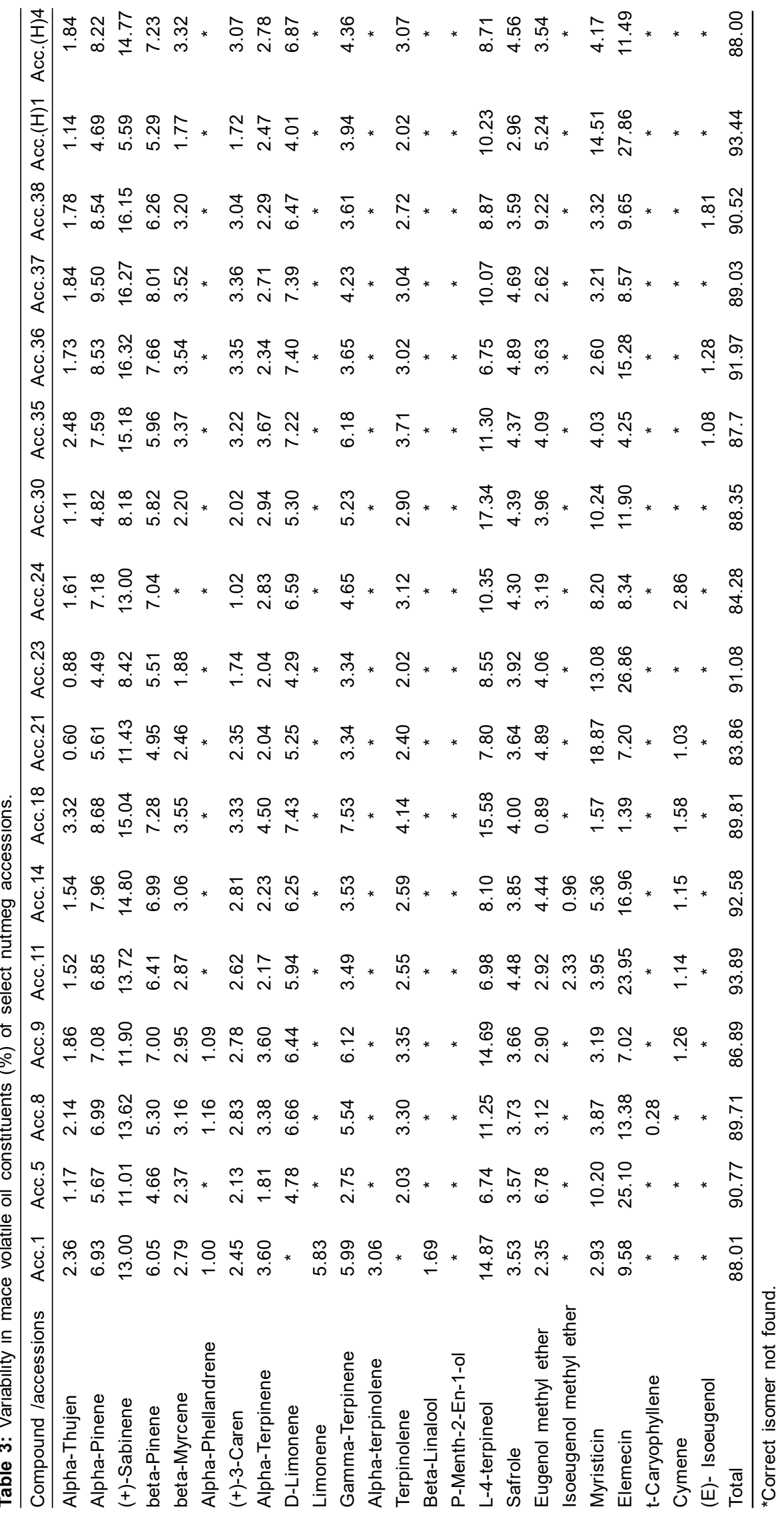




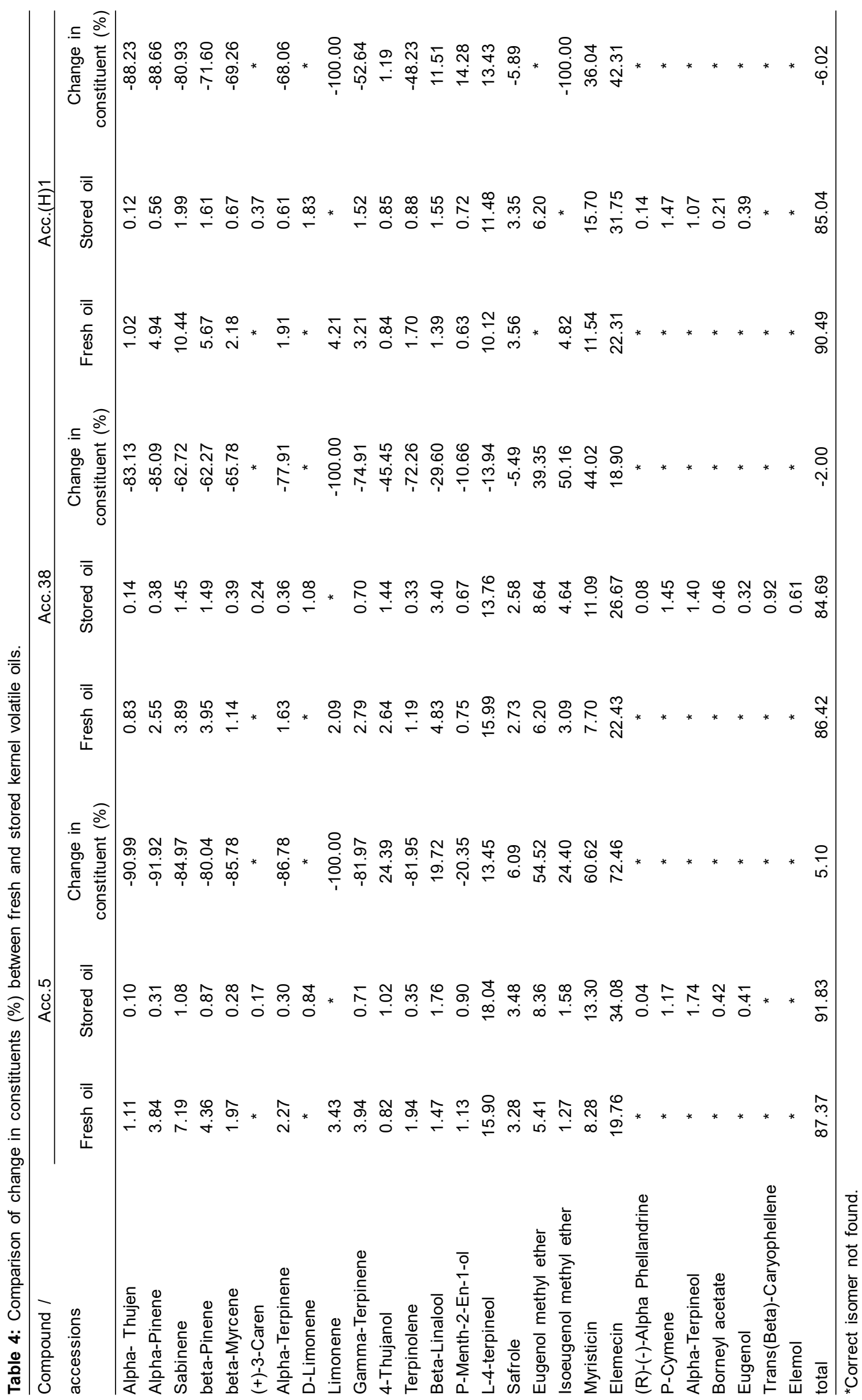




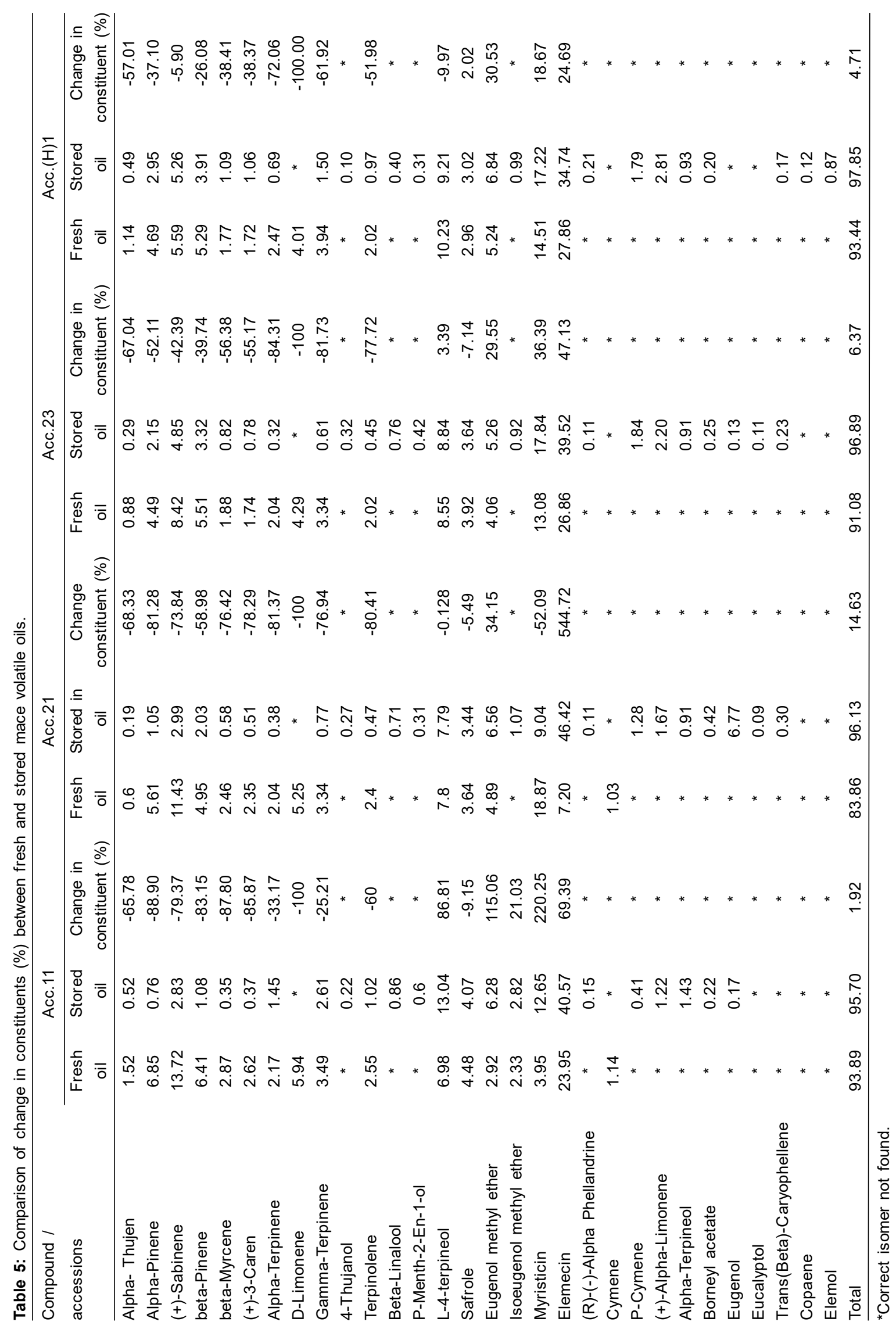




\section{CONCLUSION}

Chemoprofiling of core nutmeg germplasm recorded great variation for volatile oil, oleoresin, fixed oil as well as volatile constituents of the oil. This variation in dynamics of the quality characteristics may be due to inherent genetic makeup of the tree. Genotypes having higher levels of specific volatile compounds could be utilised by different sectors viz., food, cosmetics, traditional systems of medicine and pharmaceuticals. Storage of nutmeg volatile oils for one year under refrigerator (at $4^{\circ} \mathrm{C}$ ) exhibited changes in the aroma profile when compared to fresh oils.

\section{REFERENCES}

Abdurrasheed, K.M. and Janardanan, C. (2009). Chemical composition of nutmeg and mace (Myristica fragrans Houtt.) from Tellicherry and Kannur regions, Kerala. J. Spices Aromatic Crops. 18: 108-110.

AOAC [Association of Official Agricultural Chemists], (1975). Official Method of Analysis of AOAC International (12 $2^{\text {th }} \mathrm{Ed}$.). Association of official Analytical Chemists, Washington. p. 112.

ASTA [American Spice Trade Association], (1968). Official Method of Analysis of AOAC International ( $2^{\text {nd }}$ Ed.). American Spice Trade. P. 128.

Chirathaworn, C., Kongcharoensuntorn, W., Dechdoungchan, T., Lowanitchapat, A., Sanguanmoo, P. and Poovorawan, Y. (2007). Myristica fragrans Houtt. methanolic extract induces apoptosis in a human leukaemia cell line through
SIRT1 mRNA down regulation. Journal of Medical Association Thailand. 90: 2422-2428.

Clevengers, J.F. (1982). Apparatus for determination of volatile oil. Journal of American Pharmaceutical Association. 17: 346-348.

DASD [Directorate of Arecanut and Spices Development.], Calicut. 2021. All India area and production of spices. Available at: https://www.dasd.gov.in .

Hafiz, U.J., Dong, W., Guang-Feng, W., Kaleem, Q.M., Chang-Qing, D. and Ying, S. (2019). Post storage changes of volatile compounds in air and sun dried raisins with different packaging materials using HS-SPME with GC/MS. Food Research International. 119: 23-33.

Kapoor, I.P.S., Bandana, S., Gurdip, S., Carola, S., De-Heluani, M.P., De-Lampasona, Cesar and Catalan, A.N. (2013). Chemical composition and antioxidant activity of essential oil and oleoresins of nutmeg (Myristica fragrans Houtt.) fruits, International Journal of Food Properties. 16: 1059-1070. DOI: 10.1080/10942912.2011.576357.

Lawrence, B.M. (2000). Progress in essential oil. Perfumer Flavourist. 25: 66-68.

Sharma, S.K., Ali, M., Ansari, S.H. and Gupta, J. (2000). Evaluation of Indian herbal hepatoprotective drugs. Hamdard Medicus. XI, III, 2, p. 45.

SPSS [Statistical Package for Social Sciences], (2007). SPSS version 16. As implemented by the Indian Agricultural Statistics Research Institute, New Delhi, India. P. 112.

Warsito, M.F. (2021). A Review on Chemical Composition, Bioactivity and Toxicity of Myristica fragrans Houtt. Essential Oil. 32: 304-313. 